\title{
The effect of the quality and size of host aphid species on the biological characteristics of Aphidius colemani (Hymenoptera: Braconidae: Aphidiinae)
}

\author{
Marcus Vinicius SAmPaiO*, Vanda Helena Paes BUenO and Bruno Freitas De CONTi \\ Universidade Federal de Lavras, Departamento de Entomologia, Caixa postal 3537, CEP 37200-000, Lavras-MG, Brazil; \\ e-mail: vhpbueno@ufla.br
}

Key words. Aphidius colemani, Aphis gossypii, Aphidiidae, Aphidiinae, Braconidae, Brevicoryne brassicae, fitness, host quality, Myzus persicae, parasitoid, Rhopalosiphum maidis, Schizaphis graminum

\begin{abstract}
A suitable host provides, at least, the minimum nutritional and physiological conditions for the development of the immature stages of a parasitoid. Host quality may influence the developmental time, mortality rate, longevity and fecundity of parasitoids. This work evaluates the suitability and quality of Aphis gossypii Glover, Brevicoryne brassicae (Linné), Myzus persicae (Sulzer), Rhopalosiphum maidis (Fitch) and Schizaphis graminum (Rondani) as hosts for Aphidius colemani Viereck. Twenty second-instar nymphs of each aphid species were exposed to parasitism for one hour, and then kept in a climatic chamber at $22 \pm 1{ }^{\circ} \mathrm{C}, 70 \pm 10 \%$ RH and a $12 \mathrm{~h}$ photophase. The aphid B. brassicae was unsuitable for the development of $A$. colemani. The different aphid host species varied in size: $M$. persicae $>(R$. maidis $=S$. graminum $)>A$. gossypii. Parasitoid fitness decreased accordingly when reared on (M. persicae $=R$. maidis $)>S$. graminum $>$ A. gossypii. Large hosts seem to be better than small hosts based on parasitoid size. Egg load of $A$. colemani was related probably more on the ability of the parasitoid larva to obtain nutritional resources from the different host species than on host size.
\end{abstract}

\section{INTRODUCTION}

Host suitability and host quality directly affect development, mortality, longevity and fecundity of parasitoids (Roitberg et al., 2001). Host suitability is a characteristic of a species or host population, which provides minimal physiological and nutritional requirements for the immature development of the parasitoid. Host quality, on the other hand, is an inherent characteristic of each host determined by quantitative and qualitative differences, which affect the nutritional resources available to the parasitoid beyond the minimum required for development (Mackauer et al., 1996).

Large hosts are normally a better quality and result in the development of parasitoids with large bodies that are at a competitive advantage compared to their smaller conspecifics both in the laboratory (Cloutier et al., 2000; Chau \& Mackauer, 2001, Sagarra et al., 2001) and the field (Kazmer \& Luck, 1995; West et al., 1996; Ellers et al., 2001). Quality vs. size relationships of aphid hosts for parasitoid fitness indicate that some components are directly related to host size while others, like reproductive period and longevity, are not (Sequeira \& Mackauer, 1992, 1994). However, this relationship has been determined using different instars of the same host, with relatively few investigations comparing different host species in terms of their size and quality for aphid parasitoids (Mackauer et al., 1996).

The length of the hind tibia is considered to be a good indicator of an aphid (Nicol \& Mackauer, 1999; van Emden \& Kifle, 2002), or aphidiine parasitoid's size
(Nicol \& Mackauer, 1999). While, for fecundity evaluation, the number of eggs in the ovarioles (egg load) at emergence is widely used as an indicator of potential reproductive performance and normally directly related to parasitoid size (Chau \& Mackauer, 2001; van Emden \& Kifle, 2002).

The parasitoid Aphidius colemani Viereck has a wide range of aphid host species; it is one of the dominant species attacking aphid species in South America (Starý et al., 2007), and the main natural enemy used in the biological control of Aphis gossypii Glover and Myzus persicae (Sulzer) in Europe (van Lenteren, 2003). The wide host range of $A$. colemani allows it to be used as a model for determining how the size of different host species influences parasitoid fitness.

In this study the suitability and quality of five aphid host species for the generalist parasitoid $A$. colemani was evaluated, in order to determine the effect of host size and quality on different biological characteristics of the parasitoid.

\section{MATERIAL AND METHODS}

\section{Aphid rearing}

The aphid species evaluated as hosts for $A$. colemani were $A$. gossypii, B. brassicae, M. persicae, $R$. maidis, and $S$. graminum, and were obtained from different sources: A. gossypii from a laboratory culture reared on cucumber plants (Cucumis sativus L.), under natural temperatures and photoperiod; B. brassicae and M. persicae from kale (Brassica oleracea var. acephala L.) growing in the field were placed on sections of leaf of the host plants on $1 \%$ agar/water solution in $15 \mathrm{~cm}$ Petri dishes and kept

\footnotetext{
* Present adress: Universidade Federal de Uberlândia, ICIAG, Campus Umuarama, Caixa postal 593, CEP 38400-902,
} Uberlândia-MG, Brazil; e-mail: mvsampaio@iciag.ufu.br 
in a climatic chamber at $25 \pm 1^{\circ} \mathrm{C}$ and a $12 \mathrm{~h}$ photophase; $R$. maidis and $S$. graminum from laboratory cultures on sorghum (Sorghum bicolor L.) were placed on sections of leaf with one of the ends dipped in water in $50 \mathrm{ml}$ plastic cups, at $25 \pm 2{ }^{\circ} \mathrm{C}$ and a $12 \mathrm{~h}$ photophase. The nymphs of standard age used in the experiments, were collected after $24 \mathrm{~h}$ from 30 to 50 adult females of each aphid species kept in $15 \mathrm{~cm}$ diameter Petri dishes on leaf sections of the plant species on which they were reared, on a $1 \%$ agar/water solution at $25 \pm 1{ }^{\circ} \mathrm{C}$ and a $12 \mathrm{~h}$ photophase. The adult aphids were removed after $24 \mathrm{~h}$ and the nymphs exposed to parasitoids when they reached the $2^{\text {nd }}$ instar and were approximately $48 \mathrm{~h}$ old. The presence of exuviae indicated the nymphs were in the $2^{\text {nd }}$ instar. In order to avoid including $3^{\text {rd }}$ instar nymphs only similar sized $2^{\text {nd }}$ instar nymphs of each aphid species were chosen and presented to the parasitoid.

\section{Rearing of $A$. colemani}

The parasitoid was collected from mummies of Aphis spiraecola Patch on Citrus sinensis (L.) plants growing on the campus of the Universidade Federal de Lavras. A. colemani was reared on colonies of $S$. graminum infesting sorghum plants in a climatically controlled room in which the temperature ranged between $19-25^{\circ} \mathrm{C}$ and at a $12 \mathrm{~h}$ photophase. Pairs of parasitoids were mated in $10 \times 8 \mathrm{~mm}$ glass tubes and only those females that mated were used in the experiments.

\section{Host suitability and host quality}

The suitability and quality of $A$. gossypii, B. brassicae, $M$. persicae, $R$. maidis and $S$. graminum as hosts for A. colemani were determined in climatic chambers at $22 \pm 1{ }^{\circ} \mathrm{C}, 70 \pm 10 \%$ $\mathrm{RH}$ and a $12 \mathrm{~h}$ photophase. The whole experiment was assembled over five consecutive days, using the same A. colemani cohort.

A 24-48 h old mated female of the parasitoid was released in a $5 \mathrm{~cm}$ diameter Petri dish containing twenty $2^{\text {nd }}$ instar nymphs of each aphid species on a $4 \mathrm{~cm}$ foliar disc of the host plant on which they were reared, floating on a $1 \%$ agar/water solution. The female was removed after one hour and the aphids kept under the same climatic conditions until mummy formation. Ten females of the parasitoid were evaluated for each aphid species. The aphids were transferred to other Petri dishes containing new foliar disc five days after parasitism. After formation, mummies were kept singly in $10 \times 8 \mathrm{~mm}$ glass tubes until adult emergence, when the adults were fed a single droplet of honey and a droplet of water daily, by placing the droplets on the inside of the tube. The experiment was checked daily to evaluate the mummy formation, emergence and longevity of the parasitoid.

\section{Host and parasitoid size}

Length of the hind right tibia of $2^{\text {nd }}$ instar nymphs of each aphid species was used as a measure of size of the host exposed to the parasitoid. The tibia of aphids of the same cohort as those exposed to the parasitoid were measured. The tibia of an aphid was removed and placed in a drop of $70 \%$ alcohol on a microscope slide, covered with a cover slip and observed under a microscope at $100 \times$ magnification and measured with the aid of an ocular micrometer scale. Tibia of fifteen $2^{\text {nd }}$ instar nymphs of each aphid species were measured.

Hind right tibia of fifteen females and fifteen males of the parasitoid reared on each aphid species were also measured, using the same method.

\section{Egg load at emergence}

Females of $A$. colemani reared on each aphid species were placed in $70 \%$ alcohol $1-2 \mathrm{~h}$ after emergence, dissected and the number of eggs in their ovarioles (egg load) counted and used as an indicator of the potential fecundity of the parasitoid. Ovarioles were separated from the rest of the gaster under a stereoscopic microscope and dissected in lactophenol blue colourant, which made the eggs more visible and easier to count (Monguí et al., 1986). All eggs, not only the mature eggs, in both ovarioles were counted under an optical microscope at $100 \times$ magnification following the method proposed by van Emden \& Kifle (2002). Ten to fifteen females of $A$. colemani reared from each host species were evaluated.

\section{Statistical analysis}

The percentage parasitism is based on the number of aphid mummies that formed. The host and parasitoid size; the number of eggs in the ovarioles of A. colemani females; and the developmental time of the immature stage and adult longevity of parasitoids reared on each aphid species, were also analyzed. The percentage of parasitism, parasitoid emergence and sex ratio (percentage of female offspring) were calculated for each Petri dish $(\mathrm{n}=10)$. Even though pairing was observed, sperm may not have been passed to the female, resulting in only male offspring, thus the percentage of females was presented in two ways, one based on all the results and one for only those females that produced at least one female offspring. This was done because the production of daughters is the simplest way to be sure that a female parasitoid has mated. All the results for the parasitoids that emerged were used for the evaluation of development time, and those for 31-50 individuals of both sexes for determining adult longevity. A completely randomized design, using a $2 \times 4$ factorial scheme $(2$ sexes $\times 4$ hosts), was used to compare the size of the males and females of A. colemani. A similar randomized design with 4 treatments (hosts) was used to compare the other variables. All the data was analyzed using analysis of variance, and an F test. The means were compared using Tuckey's multiple range test and a 5\% probability.

\section{RESULTS}

\section{Percentage of parasitism, percentage emergence and sex ratio of $A$. colemani}

The percentage of parasitism of the hosts A. gossypii, $M$. persicae, $R$. maidis and $S$. graminum varied from 21.2 to $93.8 \%$ and the percentage emergence from 96.1 to $100 \%$ (Table 1). Parasitism of $M$. persicae was lower than those of A. gossypii, R. maidis and S. graminum. Parasitized B. brassicae did not mummify and $20.5 \%$ of the aphids contained dead $3^{\text {rd }}$ instar larvae of $A$. colemani, which had survived until after the stage when the parasitoid larva feeds on host tissues and organs and only the host cuticle is left. When parasitizing this host all the $A$. colemani larvae died and were darkly coloured, which is a characteristic of "incomplete parasitism".

The sex ratio (percentage of female offspring) of $A$. colemani parasitizing the host species varied from 57.0 to 72.5 when all the offspring were included in the analysis, and from 47.7 to 65.3 when only those broods that included at least one female were used (Table 1).

\section{Host size}

The hind tibial length of the aphid hosts varied from $0.226 \mathrm{~mm}$ in $A$. gossypii to $0.400 \mathrm{~mm}$ in $M$. persicae, with intermediate values for $R$. maidis and $S$. graminum with intermediate values (Table 2). The tibia of $B$. brassicae measured $0.370 \mathrm{~mm}$ (i.e., shorter than that of $M$. 
TABLE 1. Percentage parasitism, parasitoid emergence and sexual ratio (percentage of female offspring) of Aphidius colemani reared on different hosts at $22 \pm 1^{\circ} \mathrm{C}, 70 \pm 10 \% \mathrm{RH}$ and a $12 \mathrm{~h}$ photophase.

\begin{tabular}{ccccc}
\hline \multirow{2}{*}{ Host } & \multicolumn{4}{c}{ A. colemani (n) } \\
\cline { 2 - 5 } & \% Parasitism & \% Emergence & \% Females ${ }^{1}$ & \% Females $^{2}$ \\
\hline A. gossypii & $78.5(10)$ & $97.8(9)$ & $57.0(9)$ & $57.0(9)$ \\
B. brassicae & $20.5 *(10)$ & - & - & - \\
M. persicae & $21.2(10)$ & $100(10)$ & $59.6(8)$ & $47.7(10)$ \\
R. maidis & $93.8(10)$ & $100(10)$ & $72.5(9)$ & $65.3(10)$ \\
S. graminum & $77.8(10)$ & $96.1(9)$ & $62.9(8)$ & $55.9(9)$ \\
\hline
\end{tabular}

* Failed to complete development, not included in the statistical analysis. ${ }^{1}$ Only replicates in which there was at least one female offspring were used. ${ }^{2}$ All replicates.

persicae and longer than that of the other aphid species). Thus, there was a descending gradient in size among the host aphid species: $M$. persicae $>B$. brassicae $>(R$. maidis $=S$. graminum $)>A$. gossypii.

\section{Size of female and male $A$. colemani}

In the case of parasitoid size there was a significant interaction between sex and host species. Tibia size in $A$. colemani females was large when reared on large hosts (Table 2), and showed the same descending gradient in size as the hosts $M$. persicae $>(R$. maidis $=S$. graminum $)$ $>A$. gossypii. In the case of males they were largest when reared on $M$. persicae and $R$. maidis and smallest on $A$. gossypii, with a descending gradient in size corresponding to (M. persicae $=R$. maidis $)>S$. graminum $>A$. gossypii (Table 2). Tibia of females were significantly longer than those of males when reared on A. gossypii, those of the males significantly longer than those of females when reared on $R$. maidis; and similar in length in both sexes when reared on $M$. persicae and $S$. graminum (Table 2).

\section{Egg load at emergence of $A$. colemani}

There were significantly fewer eggs in the ovarioles of A. colemani reared on A. gossypii (139.1) compared to those reared on other aphid species $(226.1 ; 213.7$ and 217.2 eggs for $A$. colemani reared on $M$. persicae, $R$. maidis and $S$. graminum, respectively) (Table 2), among which there were no significant differences.

\section{Development time and adult longevity of $\boldsymbol{A}$. colemani}

The development time of $A$. colemani varied from 11 to 15 days when reared on $A$. gossypii and $S$. graminum, and from 12 to 14 days when reared on $M$. persicae and $R$. maidis (Table 2). The average development time of $A$. colemani (means \pm standard error) was $12.5 \pm 0.09,12.2$ $\pm 0.10,12.1 \pm 0.03$ and $12.6 \pm 0.08$ days for females and $12.4 \pm 0.12,12.1 \pm 0.09,12.1 \pm 0.04$ and $12.4 \pm 0.08$ days for males when reared on $A$. gossypii, M. persicae, $R$. maidis and $S$. graminum, respectively.

The maximum longevity of $A$. colemani was $14,12,17$ and 17 days for females and 19, 18, 19 and 18 days for males when reared on $A$. gossypii, $M$. persicae, $R$. maidis and $S$. graminum, respectively (Fig. 1). The adults started to die before the $10^{\text {th }}$ day in the case of females and after the $13^{\text {th }}$ day in males. This indicates that males of $A$. colemani have a greater longevity than females when reared on all four aphid species (Fig. 1). The average adult longevity of $A$. colemani (means \pm standard error) was 10.8 $\pm 0.53,10.3 \pm 0.56,12.6 \pm 0.72$ and $12.8 \pm 0.72$ days for females and $13.3 \pm 0.49,14.3 \pm 0.41,15.3 \pm 0.35$ and $14.5 \pm 0.34$ days for males when reared on A. gossypii, $M$. persicae, $R$. maidis and $S$. graminum, respectively.

\section{DISCUSSION}

Of the five aphid species evaluated as hosts for $A$. colemani (A. gossypii, B. brassicae, M. persicae, R. maidis and $S$. graminum) only $B$. brassicae was unsuitable. On this host, A. colemani failed to complete its development.

TABLE 2. Length of tibia of host aphids and male and female of Aphidius colemani, number of eggs in the ovarioles of parasitoid females at emergence, and immature development times (range of days) when reared on different hosts at $22 \pm 1{ }^{\circ} \mathrm{C}, 70 \pm 10 \% \mathrm{RH}$ and a $12 \mathrm{~h}$ photophase.

\begin{tabular}{|c|c|c|c|c|c|c|}
\hline \multirow{3}{*}{ Hosts } & \multicolumn{3}{|c|}{ Length of tibia $(\mathrm{mm})$} & \multirow{3}{*}{$\begin{array}{l}\text { Number of eggs/female } \\
\text { parasitoid (n) }\end{array}$} & \multirow{2}{*}{\multicolumn{2}{|c|}{ Development time (n) }} \\
\hline & \multirow{2}{*}{$\begin{array}{l}\text { Aphids } \\
(\mathrm{n}=15)\end{array}$} & \multicolumn{2}{|c|}{ Parasitoids } & & & \\
\hline & & $\begin{array}{l}\text { Females } \\
(\mathrm{n}=15)\end{array}$ & $\begin{array}{l}\text { Males } \\
(\mathrm{n}=15)\end{array}$ & & Female & Male \\
\hline A. gossypii & $0.226 \pm 0.008 \mathrm{D}$ & $0.537 \pm 0.007 \mathrm{Ca}$ & $0.516 \pm 0.008 \mathrm{Cb}$ & $139.1 \pm 12.4 \mathrm{~B}(15)$ & $12-15(78)$ & $11-15(55)$ \\
\hline B. brassicae & $0.370 \pm 0.003 \mathrm{~B}$ & - & - & - & - & - \\
\hline M. persicae & $0.400 \pm 0.006 \mathrm{~A}$ & $0.648 \pm 0.006 \mathrm{Aa}$ & $0.635 \pm 0.008 \mathrm{Aa}$ & $226.1 \pm 9.0 \mathrm{~A}(10)$ & $12-13(17)$ & $12-14(25)$ \\
\hline R. maidis & $0.294 \pm 0.004 \mathrm{C}$ & $0.590 \pm 0.007 \mathrm{Bb}$ & $0.623 \pm 0.006 \mathrm{Aa}$ & $213.7 \pm 15.0 \mathrm{~A}(15)$ & $12-14(114)$ & $12-13(63)$ \\
\hline S. graminum & $0.284 \pm 0.010 \mathrm{C}$ & $0.580 \pm 0.008 \mathrm{Ba}$ & $0.569 \pm 0.006 \mathrm{Ba}$ & $217.2 \pm 16.2 \mathrm{~A}(15)$ & $12-15(72)$ & $12-14(54)$ \\
\hline
\end{tabular}

* Means followed by the same capital letter in columns and small letters in rows are not statistically significant, Tukey's multiple range test at $5 \%$. 

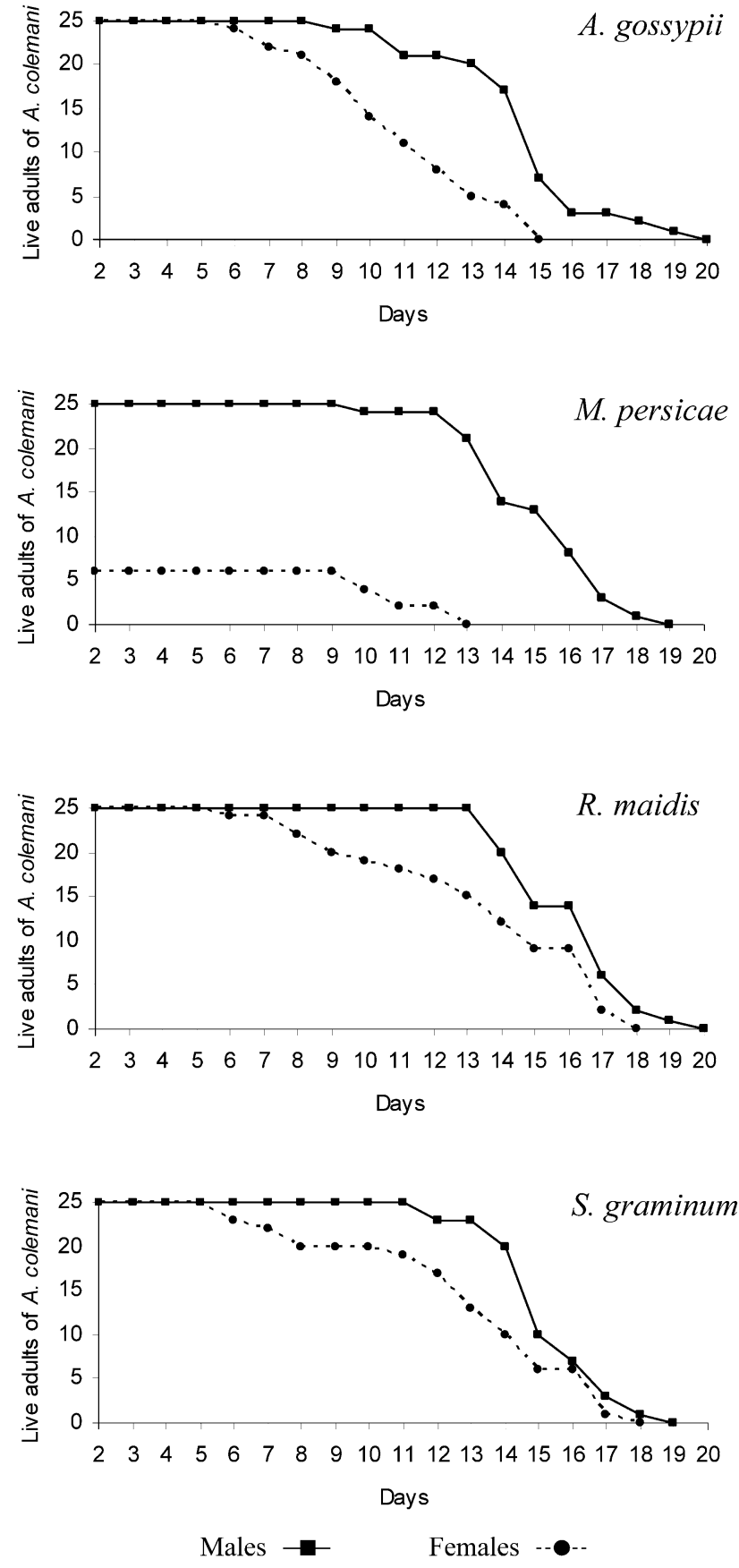

Fig. 1. Adult longevity of Aphidius colemani reared on different hosts at $22 \pm 1^{\circ} \mathrm{C}, 70 \pm 10 \% \mathrm{RH}$ and a $12 \mathrm{~h}$ photophase.

According to Starý (1989), this phenomenon is quite common in aphidiine parasitoids and can vary between host populations. Our results differ from those of Elliott et al. (1994), who observed that $25 \%$ of the larvae of $A$. colemani in $B$. brassicae reached the mummy stage and $5 \%$ reached the adult stage, indicating a low host quality. Although there are some reports of $A$. colemani parasitizing $B$. brassicae in the field, it is always at a low level (Vaz et al., 2004; Starý et al., 2007), which also indicates that $B$. brassicae is not a good host for $A$. colemani.

The levels of parasitism by $A$. colemani recorded in this study are similar to those found by van Steenis (1993) and Sampaio et al. (2001), who report higher percentages of parasitism of $A$. gossypii than M. persicae, which differs from the percentages reported by Elliott et al. (1994), with higher percentages of parasitism of $S$. graminum than of $A$. gossypii and $R$. maidis. In our study $A$. colemani showed promising percentages parasitism and emergence for the biological control of A. gossypii, $M$. persicae, R. maidis and S. graminum.

The successful development of the immature stage of parasitoids depends upon the host's suitability and quality. In good quality hosts the accumulation of reserves occurs throughout the parasitoid's larval development, influencing adult biological characteristics, like longevity and fecundity (Boggs, 1981). Host quality is in general associated with host size, with larger hosts having more resources, resulting in a greater parasitoid fitness (Nicol \& Mackauer, 1999; Chau \& Mackauer, 2001).

Our results show that $A$. colemani parasitoids reared on large hosts are also large and have a greater reproductive potential. Comparison of the parasitoids reared on $A$. gossypii, the smallest, with M. persicae, the largest host, revealed significant differences in both parasitoid fitness variables. In this case, parasitoids reared on M. persicae were larger and had more eggs in the ovarioles.

Hind tibial length is not the most accurate method of estimating aphid mass. In species differing in body shape and size (i.e., volume), hind tibial length gives an approximate measure of mass (Nicol \& Mackauer, 1999). We used hind tibial length because it is easy to measure, however, it may have biased the results due to differences in body size and shape among the aphid hosts. However, our results for $A$. colemani are similar to those of Ode et al. (2005) who weighed A. colemani reared on different host species. These authors used M. persicae, R. padi, $S$. graminum and $A$. gossypii as hosts for $A$. colemani and found that the female's weight increased with increase in weight of the host species.

In addition to host size the interaction of the host with parasitoid larvae determines host quality, i.e. parasitoid reproductive period and longevity are not related to host size but to the capacity of parasitoid larva to use the resources available in different stages of the same host aphid species (Sequeira \& Mackauer, 1992, 1994). There is a clear lack of a linear relationship between host size and parasitoid fitness when reared on different host stages of the same host aphid and even more so when reared on host species differing in size. The importance of resource availability for parasitoid larvae can be observed in $A$. colemani reared on $M$. persicae and $S$. graminum which differ in size. The parasitoids reared on the larger of these two species, M. persicae, were larger than those reared on $S$. graminum. However, the parasitoids reared on both these host species had the same number of eggs in their ovarioles. This indicates that not only size but also the ability of the parasitoid larva to obtain resources from the different host species is an important determinant of the potential fecundity in A. colemani.

Aphidiine females are normally larger than males but both sexes have the same development time when reared 
on hosts of the same size (Sequeira \& Mackauer, 1993; Mackauer, 1996). Thus female grow faster and accumulate more resources per unit time than males. However, the size difference between males and females is greater in small hosts and decreases with increase in host size (Sequeira \& Mackauer, 1993; Mackauer, 1996). The same was found in this study. The females of $A$. colemani were bigger than the males when reared on the smallest host, $A$. gossypii, but both sexes were the same size when reared on the larger hosts, $M$. persicae and S. graminum.

The relative size of the males of $A$. colemani reared on $R$. maidis differs from that expected. Second instar nymphs of $R$. maidis are smaller than those of $M$. persicae and the same size as those of $S$. graminum. Males of $A$. colemani reared on $R$. maidis were the same size as those reared on $M$. persicae and bigger than those reared on $S$. graminum. They were also bigger than females, when reared on $R$. maidis. It is unusual in Hymenoptera parasitoids for males to be larger than females (Mackauer, 1996), so the larger size of males of $A$. colemani when reared on $R$. maidis results probably from individual variation.

A. colemani reared on a good quality host, M. persicae, produced fewer descendents $(21.2 \%$ parasitism), than those reared on a poor quality host, A. gossypii $(78.5 \%$ parasitism). These results are similar to those obtained by Sampaio et al. (2001), who report that $A$. colemani prefers to oviposit in $A$. gossypii over $M$. persicae. The better quality host should be the preferred by a parasitoid (Godfray, 1994), but, according to Chau \& Mackauer (2001) and Henry et al. (2005), host quality is not a good predictor of host preference as hosts of good quality are not always the preferred hosts of parasitoids. Ode et al. (2005) found an association between A. colemani host preference and the survival of its immature stages; however, larval mortality of this parasitoid was not evaluated in our study, only parasitoid emergence was recorded, which indicates parasitoid pupal mortality. Additional studies on the relationship between mortality of larval stages and host preference in A. colemani and other species of aphidiine may help resolve the evolutionary aspects of host preference.

Thus, for $A$. colemani, the host quality of the aphids studied in decreasing order was (M. persicae $=R$. maidis) $>S$. graminum $>A$. gossypii. Host size and the ability of parasitoid larva to obtain nutritional resources from a particular host species determined the quality of the host for the parasitoid. Large hosts are better hosts than small ones in terms of $A$. colemani size. However, the ability of A. colemani larvae to obtain nutritional resources from their hosts was important for the fecundity of the parasitoid.

\section{REFERENCES}

BogGS C.L. 1981: Nutritional and life-history determinants of resource allocation in holometabolous insects. Am. Nat. 117: 692-709.

Chau A. \& Mackauer M. 2001: Preference of the aphid parasitoid Monoctonus paulensis (Hymenoptera: Braconidae,
Aphidiinae) for different aphid species: female choice and offspring survival. Biol. Control 20: 30-38.

Cloutier C., Duperron J., Tertuliano M. \& Mcneil J.N. 2000: Host instar, body size and fitness in the koinobiontic parasitoid Aphidius nigripes. Entomol. Exp. Appl. 97: 29-40.

Ellers J., Bax M. \& van Alphen J.J.M. 2001: Seasonal changes in female size and its relation to reproduction in the parasitoid Asobara tabida. Oikos 92: 309-314.

Elliott N.C., French B.W., Burd J.D., Kindler S.D. \& Reed D.K. 1994: Parasitism, adult emergence, sex ratio, and size of Aphidius colemani (Hymenoptera: Aphidiidae) on several aphid species. Great Lakes Entomol. 27: 137-142.

Godfray H.C.J. 1994: Parasitoids: Behavioral and Evolutionary Ecology. Princeton University, Chichester, 473 pp.

Henry L.M., Gillespie D.R. \& Roitberg B.D. 2005: Does mother really know best? Oviposition preference reduces reproductive performance in the generalist parasitoid Aphidius ervi. Entomol. Exp. Appl. 116: 167-174.

KAZMER D.J. \& LUCK R.F. 1995: Field test of size-fitness hypothesis in the egg parasitoid Trichogramma pretiosum. Ecology 76: 412-425.

MACKAUER M. 1996: Sexual size dimorphism in solitary parasitoid wasps: influence of host quality. Oikos 76: 265-272.

Mackauer M., Michaud J.P. \& VölKL W. 1996: Host choice by aphidiid parasitoids (Hymenoptera; Aphidiidae): host recognition, host quality, and host value. Can. Entomol. 128: 959-980.

Mongui B., Luque J.E. \& Escobar J. 1986: Biología de Aphidius colemani (Hymenoptera: Aphidiidae) parasitoide de Myzus persicae (Homoptera: Aphididae) en crisantemos de la Sabana de Bogotá. Rev. Colomb. Entomol. 12: 46-53.

Nicol C.M.Y. \& Mackauer M. 1999: The scaling of body size and mass in a host-parasitoid association: influence of host species and stage. Entomol. Exp. Appl. 90: 83-92.

Ode P.J., Hopper K.R. \& Coll M. 2005: Oviposition vs. offspring fitness in Aphidius colemani parasitizing different aphid species. Entomol. Exp. Appl. 115: 303-310.

Roitberg B.D., Boivin G. \& Vet L. 2001: Fitness, parasitoids, and biological control: an opinion. Can. Entomol. 133: 429-438.

Sagarra L.A., Vincent C. \& Stewart R.K. 2001: Body size as an indicator of parasitoid quality in male and female Anagyrus kamali (Hymenoptera: Encyrtidae). Bull. Entomol. Res. 91: 363-367.

Sampaio M.V., Bueno V.H.P. \& van Lenteren J.C. 2001: Preferência de Aphidius colemani Viereck (Hymenoptera: Aphidiidae) por Myzus persicae (Sulzer) e Aphis gossypii Glover (Hemiptera: Aphididae). Neotrop. Entomol. 30: 665-660.

Sequeira R. \& Mackauer M. 1992: Nutritional ecology of an insect host-parasitoid association: the pea aphid-Aphidius ervi system. Ecology 73: 183-189.

Sequeira R. \& Mackauer M. 1993: The nutritional ecology of a parasitoid wasp, Ephedrus californicus Baker (Hymenoptera: Aphidiidae). Can. Entomol. 125: 423-430.

Sequeira R. \& Mackauer M. 1994: Variation in selected lifehistory parameters of the parasitoid wasp, Aphidius ervi: influence of host developmental stage. Entomol. Exp. Appl. 71: $15-22$.

STARÝ P. 1989: Incomplete parasitization in aphids and its role in pest management (Hymenoptera: Aphidiidae). Acta Entomol. Bohemoslov. 86: 356-367.

Starý P., Sampaio M.V. \& Bueno V.H.P. 2007: Aphid parasitoids (Hymenoptera, Braconidae, Aphidiinae) and their asso- 
ciations related to biological control in Brazil. Rev. Bras. Entomol. 51: 107-118.

van Emden H.F. \& Kifle A.T. 2002: Performance of the parasitoid Aphidius colemani when reared on Myzus persicae on a fully defined artificial diet. BioControl 47: 607-616.

VAN LENTEREN J.C. 2003: Commercial availability of biological control agents. In van Lenteren J.C. (ed.). Quality Control and Production of Biological Control Agents: Theory and Testing Procedures. CABI, Cambridge, pp. 167-179.

van SteEnIs M.J. 1993: Suitability of Aphis gossypii Glov., Macrosiphum euphorbiae (Thom.), and Myzus persicae Sulz.
(Hom.: Aphididae) as host for several aphid parasitoid species (Hym.: Braconidae). IOBC/WPRS Bull. 26: 157-160.

Vaz L.A.L., Tavares M.T. \& Lomônaco C. 2004 : Diversidade e tamanho de himenópteros parasitóides de Brevicoryne brassicae L. e Aphis nerii Boyer de Fonscolombe (Hemiptera: Aphididae). Neotrop. Entomol. 33: 225-230.

West S.A., Flanagan K.E. \& Godfrey H.C.J. 1996: The relation between parasitoid size and fitness in the field, a study of Achrysocharoides zwoelferi (Hymenoptera: Eulophidae). $J$. Anim. Ecol. 65: 631-639.

Received September 18, 2007; revised and accepted May 9, 2008 